\title{
EFFECT OF HIGH PRESSURIZED CARBON DIOXIDE ON ESCHERICHIA COLI
}

\author{
IP Bateebe and O Kibazohi \\ Department of Chemical and Process Engineering, University of Dar es salaam, \\ P.O. Box 35131, Dar es salaam, Tanzania \\ kibazohi@udsm.ac.tz
}

\begin{abstract}
Carbon dioxide at high pressure can retard microbial growth and sometimes kill microorganisms depending on values of applied pressure, temperature and exposure time. In this study the effect of high pressurised carbon dioxide (HPCD) on Escherichia coli was investigated. Culture of E. coli was subjected to high pressurised carbon dioxide at 15, 25 and 35 bar, and varying exposure times of 20, 40, 60 and 90 minutes at room temperature $\left(27^{\circ} \mathrm{C}\right)$. Microbial inactivation increased with pressure and exposure time. For the first 20 minutes reduction of viable microbial cells was 18\%, 30\% and 36\% at 15, 25 and 35 bar, respectively. Higher microbial inactivation values were achieved at 40, 60, and 90 minutes. Decimal reduction times were 127, 93 and 75 minutes at 15, 25, and 35 bar, respectively. The $p H$ values of treated samples decreased with increasing pressure and treatment time from approximately neutral to 5.71 at 15 bar, and 5.02 at 35 bar. It was concluded that high pressurised carbon dioxide has antimicrobial effect on E. coli bacteria. With further studies, HPCD microbial deactivation can be used for foods preservation as a alternative technology to conventional heat pasteurisation and sterilization.
\end{abstract}

\section{INTRODUCTION}

Since time immemorial, microbial inactivation has mainly been achieved by application of heat for either pasteurization or sterilization purposes. Both methods have negative effects of destroying important nutrients, production of toxic-side reactions, and causing changes in physical, mechanical and optical properties of the material involved in the treatment. As a result of the above disadvantages, non-thermal processes are being sought as alternatives to thermal microbial inactivation for production of high quality foods. In accordance with the current trend, there is a growing interest in the use of high pressure $\mathrm{CO}_{2}$ for killing microorganisms (Erkmen 1997).

Microbial growth inhibition under high concentration of dissolved $\mathrm{CO}_{2}$ has long been exploited and used to preserve pasteurised or sterilised foodstuff such as beer and carbonated soft drinks. According to recent reports, HPCD does more than inhibition of microbial growth; it also inactivates microorganisms and sometimes spores (Ballestra and Cuq 1998, Devlieghere and Debevere 2000, Erkmen 2000a, 2000b, 2000c, 2000d, 2000e, 1997, Hong et al. 1997, Karaman and Erkmen 2001, Park et al. 2002). Application of HPCD at values ranging from 10 to 100 bar results in partial or complete inactivation of microorganisms depending on application time, temperature, microbial species, and the nature of the medium. Inactivation effect increases with pressure, temperature and application time (Ballestra and Cuq 1998, Erkmen 2000a, 2000b, 2000c, 2000d, 1997, Hong et al 1997). Successful study of HPCD application as a sterilisation method for food products is reported in literature. Arreola et al. (1990) successfully sterilised orange juice using HPCD method. Erkmen (2000b, 2000d) successfully eliminated Listeria monocytogenes and Enterococcus faecalis from peach, carrot juices and whole and skimmed milk.

It is important that studies be conducted to determine conditions at which high 
pressured carbon dioxide will effectively inactivate microorganisms or suppress microbial growth for food applications. Thus, the objective of this study was to investigate the inactivation rate of $E$. coli a common food spoilage bacteria, under HPCD at varying exposure time.

\section{MATERIALS AND METHODS}

\section{Nutrient broth}

Nutrient broth was prepared according to Bridson (1998) by mixing laboratory grade $2.25 \mathrm{~g}$ of mycological peptone (Biotec, Suffulk, UK), $0.9 \mathrm{~g}$ of sodium chloride, $0.15 \mathrm{~g}$ of glucose, and $0.45 \mathrm{~g}$ of yeast extract (OXOID, Hampshire, England) in 1 litre of deionised water. The broth was then sterilized in an autoclave, Sanyo model MAC-1200, Japan at $121{ }^{\circ} \mathrm{C}$ for 15 minutes before inoculation with microorganism.

\section{Bacteria culture}

E. coli was obtained from the Molecular Biology and Biotechnology Department, University of Dar es salaam. Two loopfuls of $E$. coli from nutrient agar were inoculated into $150 \mathrm{ml}$ of nutrient broth in a $500 \mathrm{ml}$ conical flask, and incubated in an incubator
(Wissenchaftlich-Technische Werkstätten $\mathrm{GmbH}$, Germany) with a shaker at $120 \mathrm{rpm}$, for 24 hours at $30{ }^{\circ} \mathrm{C}$. The resulting E. coli culture was used to inoculate a working medium by transferring $15 \mathrm{ml}$ of the culture into a new sterile $150 \mathrm{ml}$ nutrient broth in a $500 \mathrm{ml}$ conical flask. The culture was incubated for 24 hours at $30{ }^{\circ} \mathrm{C}$ in the incubator before being subjected to high pressure treatment.

\section{Pressure equipment}

A cylindrical pressure vessel (pressure tolerance 300 bar) made from stainless steel with internal diameter of $50 \mathrm{~mm}, 116 \mathrm{~mm}$ high and internal volume of $228 \mathrm{ml}$ was used. A schematic diagram of the equipment is shown in Figure 1. The pressure vessel was connected to tubing system comprised of a stainless steel tube (Swagelock, South Africa) and high pressure brass valves (Swagelock, U.K.), both with pressure rating of 150 bar. The tubing system was connected to a pressure regulator installed on the $\mathrm{CO}_{2}$ cylinder. After each experiment run, the pressure vessel was cleaned with $75 \%$ ethanol.

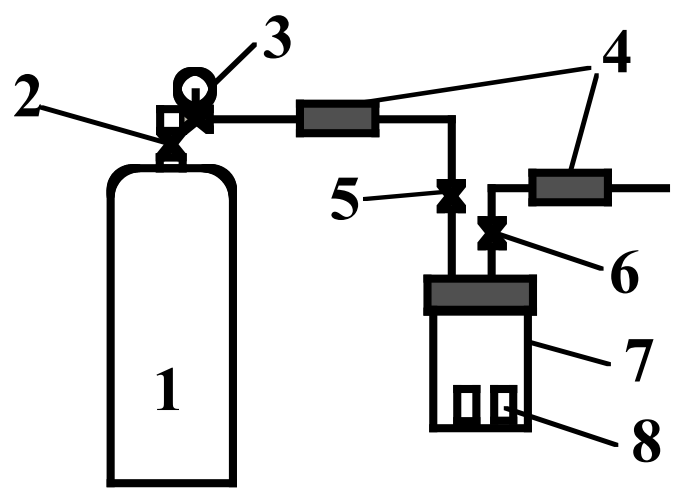

Figure 1: Schematic diagram of the apparatus used for high-pressurized $\mathrm{CO}_{2}$ treatment. $1, \mathrm{CO}_{2}$ cylinder; $2, \mathrm{CO}_{2}$ cylinder's main valve; 3 , diaphragm pressure regulator and indicator; 4, line filters; 5, line valves; 6 , Pressure vessel; 7, sample cups 


\section{Pressure Treatment}

Treatment pressure values were 15,25 , and 35 bar, each at different exposure time intervals of 20,40,60 and 90 minutes. Due to technical limit of 50 bar for the $\mathrm{CO}_{2}$ supplied by local supplier, Tanzania Oxygen, it was necessary to selection working pressure below 50 bar. Experiments were carried out in triplicates at room temperature $\left(27{ }^{\circ} \mathrm{C}\right)$ for each selected pair of pressure and exposure time and results reported as an average of ratios of surviving cells to original number of viable cells (N/No). Treatment was conducted by transferring $2 \mathrm{ml}$ of nutrient broth containing $E$. coli from the conical flask into a Plexiglas cap of $20 \mathrm{~mm}$ internal diameter and $40 \mathrm{~mm}$ high. Four caps containing the broth were place in the pressure vessel. The vessel was tightly closed and quickly connected to the tubing system. The vessel was then subjected to high pressure $\mathrm{CO}_{2}$ treatment by opening cylinder's main valve, setting the predetermined delivery pressure on the pressure regulator and opening tubing inlet linevalve. After pressure treatment the pressure was decreased by closing the cylinder's main valve and gradually reducing pressure to zero on the pressure regulator within 1 to 2 minutes. The pressure vessel was disconnected from the tubing system, transferred to a horizontal laminar flow cabinet where it was opened, the caps carefully removed, and enumeration of viable cells performed. The $1^{\text {st }}$ Plexiglas cap was removed after 20 , and the pressure vessel pressurised again for another 20 before removing the second up, the process was repeated for $3^{\text {rd }}$ and $4^{\text {th }}$. The exposure time of a cap was the sum of corresponding batch exposure times before the cap was removed from the pressure vessel.

\section{Enumeration of viable cells}

Each sample was serially diluted with saline solution up to a factor of $10^{7}$; higher dilution did not result in microbial growth. Mixing was thoroughly done by using a vortex mixer (Heidolph, Germany). The viable cell count was determined by plate count method whereby 1001 of diluted samples from the $6^{\text {th }}$ and $7^{\text {th }}$ dilutions were spread on a nutrient agar plate. A control sample from the same culture of $E$. coli was not treated with the high pressure carbon dioxide, but serially diluted and viable cell count performed in the same way. Viable microbial cell density in the control samples was $3-5 \times 10^{9} / \mathrm{ml}$. The nutrient agar plates were incubated at $30{ }^{\circ} \mathrm{C}$ for 24 hours after which all visible colonies were counted using a cell counter.

\section{pH}

A $\mathrm{pH}$ of a treated sample was measured using a $\mathrm{pH}$ meter (Inolab WTW, Germany). After taking $1 \mathrm{ml}$ for serial dilution from the treated sample of E.coli culture, the remaining $1 \mathrm{ml}$ was poured into a test tube and a $\mathrm{pH}$ probe inserted into the tube to record the $\mathrm{pH}$.

\section{RESULTS AND DISCUSSION}

Antimicrobial activity of high pressurised carbon dioxide on $E$. coli is shown in Figures 2 and 3 . It was observed that the average ratio of surviving cells to the initial viable cells decreases with exposure time for all treatment pressure values of 15,25 and 35 bar. The decrease was dependent on treatment pressure; being highest at 35 bar and lowest at 15 bar for a given exposure time. For the first 20 minutes reduction of viable microbial cells was $18 \%, 30 \%$ and $36 \%$ at 15,25 and 35 bar, respectively. After 90 minutes of HPCD treatment, reduction in viable cells was $84 \%, 89 \%$ and $94 \%$ at 15,25 and 35 bar, respectively. Similar results are reported by other researchers: Erkmen (2000d) achieved a complete inactivation of Enterococcus faecalis in physiological saline medium at the following conditions: 30.2 bar, $35{ }^{\circ} \mathrm{C}$ and $80 \mathrm{~min}$; also at $60.5 \mathrm{bar}, 35{ }^{\circ} \mathrm{C}$ and 18 min. Hong et al (1997) reduced cells of Lactobacillus sp. in Kimchi - fermented vegetable at 70 bar, $30^{\circ} \mathrm{C}$ and $200 \mathrm{~min}$. 
High level of inactivation achieved by Erkmen (2000d) and Hong et al. (1997) is might be due to difference in microorganisms, type of medium, and high pressure applied by other researchers.

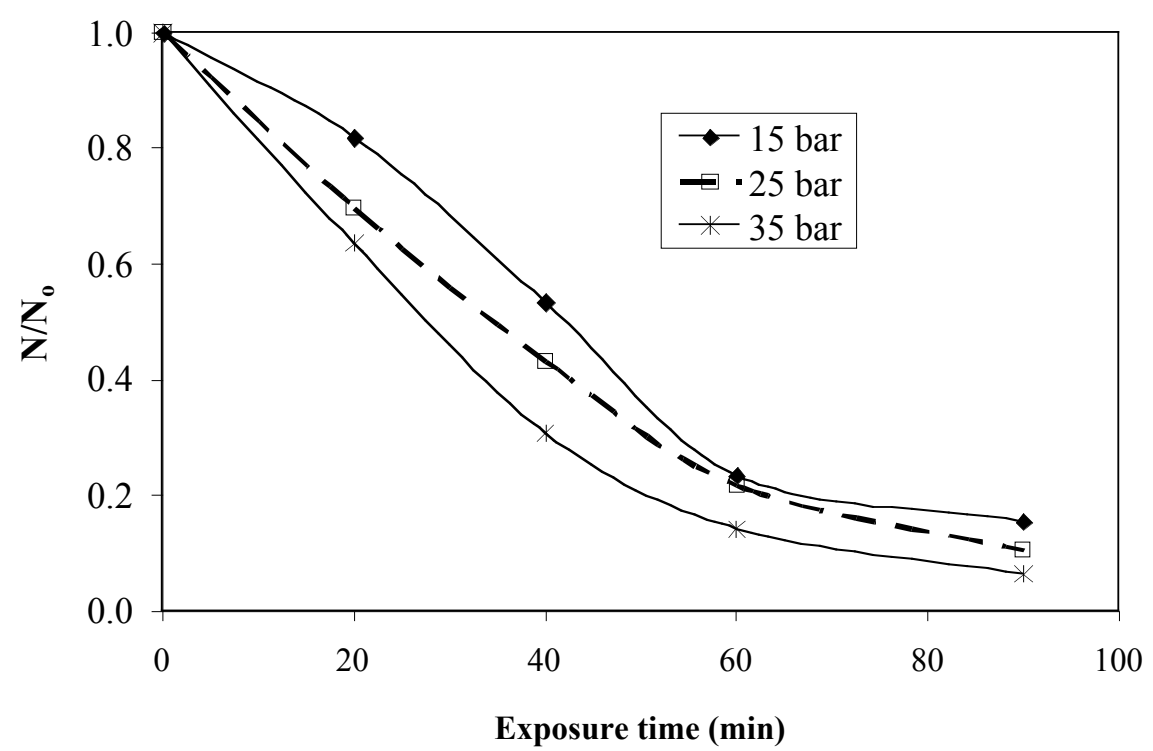

Figure 2: Variation of the ratio of surviving cells with time after treatment with high pressurized carbon dioxide.

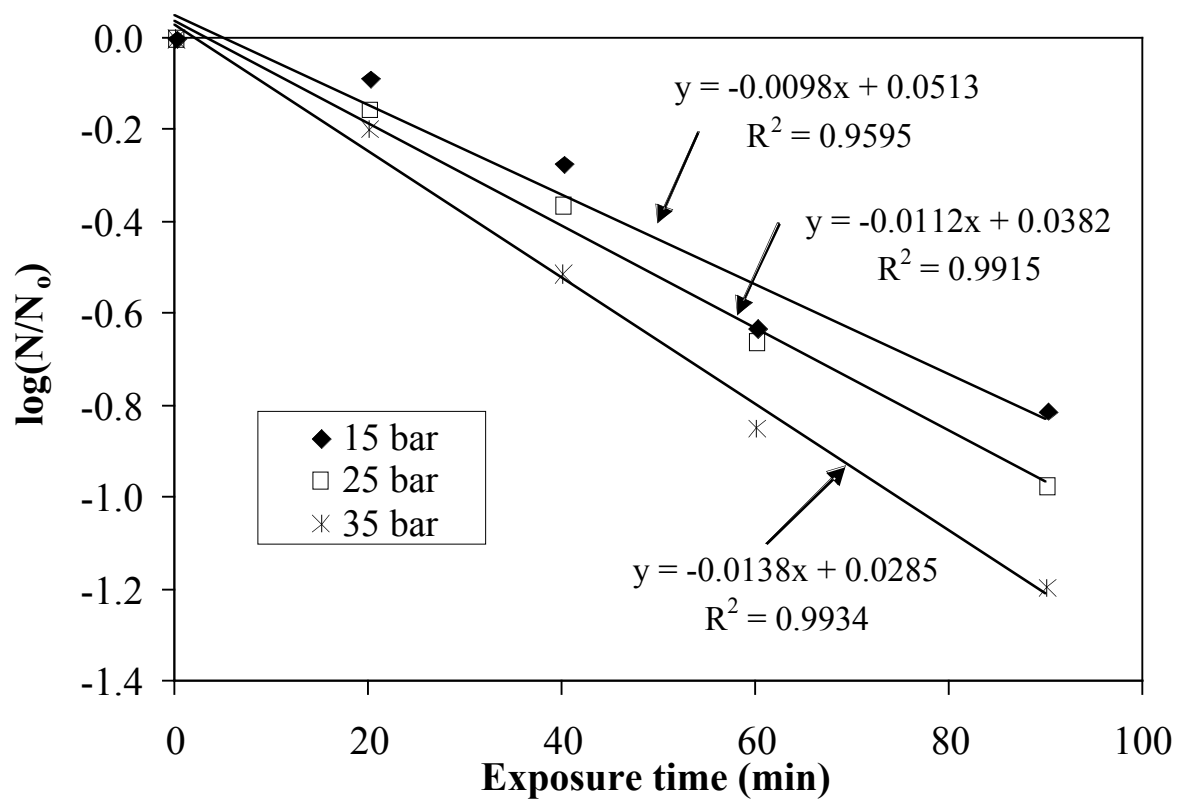

Figure 3: Relationship of the log of the ratio of surviving cells with time after treatment with high pressurized carbon dioxide. 
Figure 2 shows that relationship between the ratio of surviving cells and treatment time was not linear. But Figure 3 shows a linear relationship between the logarithm of the ratio of surviving cell and exposure time. Similar trend was observed by other researchers (Devlieghere and Debevere 2000, Erkmen 2000a, 2000b, Karaman and Erkmen 2001). As such microbial inactivation with HPCD treatment can be modelled using an exponential function in a similar manner as microbial death due to heat sterilization. Further more, Figure 3 shows that the trend lines do not pass through the origin despite high values of a square of regression coefficient $\mathrm{R}^{2}$ which was more than 0.99 for both 25 and 35 bar and 0.96 for 15 bar. Erkmen (2000a), observed a curve with two slopes during inactivation of Salmonella typhimurium. The curve had initially a small slope which lasted for less than $10 \mathrm{~min}$ at a treatment pressure of 60 bar and $40 \mathrm{~min}$ at $15 \mathrm{bar}$, followed by a higher slope. According to our unpublished results the initial slope takes place during the time when carbon dioxide is diffusing into the medium. This explains why the trend lines do not pass through the origin.
Death rate of $E$. coli was evaluated in terms of decimal reduction time using equations of trend lines in Figure 3. The decimal reduction time varied with treatment pressure and was high for low treatment pressure and vice versa. Values of decimal reduction time were 127,93 and $75 \mathrm{~min}$ at treatment pressures of 15,25 , and 35 bar, respectively. Karaman and Erkmen (2001) obtained lower decimal reduction times for PHCD treatment of $E$. coli in a nutrient broth; at a pressure of 25 bar, D-values were $27.46 \mathrm{~min}$ at $20{ }^{\circ} \mathrm{C}$ and $20.10 \mathrm{~min}$ at $30{ }^{\circ} \mathrm{C}$. The large difference between results and literature values by Karaman and Erkmen (2001) is attributed to differences in experimental procedure. Ice cooling of samples immediately after HPCD treatment by Karaman and Erkmen (2001) might have resulted into higher cell death rate. In this work exposures time evaluated as a sum of more than one treatment resulted in less actual exposure time, because once depressurized, the medium lost dissolved $\mathrm{CO}_{2}$ and a subsequent pressurization has less effect during initial diffusion period, hence less overall death rate.

Table 1: Variation of media $\mathrm{pH}$ after treatment with high pressure carbon dioxide.

\begin{tabular}{cccc}
\hline & 15 bar & 25 bar & 35 bar \\
\hline Time & $\mathrm{pH}$ & $\mathrm{pH}$ & $\mathrm{pH}$ \\
$(\mathrm{min})$ & & 6.78 & 6.77 \\
0 & 7.54 & 6.48 & 6.26 \\
20 & 5.87 & 6.27 & 6.00 \\
40 & 5.78 & 6.01 & 5.71 \\
60 & 5.76 & 5.66 & 5.02 \\
90 & 5.71 &
\end{tabular}

High pressure carbon dioxide treatment reduced $\mathrm{pH}$ of the samples as shown in Table 1. Treated media $\mathrm{pH}$ decreased below $\mathrm{pH}$ values of the original untreated samples. While original samples had $\mathrm{pH}$ values of $6.77-7.54$, the treated samples had low $\mathrm{pH}$ values below 5.71 despite the depressurization of the media after HPCD treatment. The effect was higher for the highest pressure (35 bar) with a final $\mathrm{pH}$ of 5.02 compared to 5.71 attained at a pressure of 15 bar. The decrease in $\mathrm{pH}$ was also dependent on treatment time; for each treatment pressure the lowest values were 
attained a treatment time of $90 \mathrm{~min}$. Low $\mathrm{pH}$ values were caused by formation of carbonic acid resulting from dissolved carbon dioxide in aqueous media.

\section{CONCLUSION}

The results of this study indicate that high pressure carbon dioxide has an antimicrobial activity on $E$. coli. The activity increases with increasing pressure and exposure time. Microbial inactivation follows exponential relationship and can therefore be modelled in a similar manner as heat sterilization. Application of HPCD reduces the $\mathrm{pH}$ of the medium. HPCD application need further studies for various applications, particularly in the sterilization of heat sensitive materials such as vitamins and other food components.

\section{ACKNOWLEDGEMENT}

We are grateful to the Molecular Biology and Biotechnology Department, University of Dar es Salaam for providing us with $E$. coli, without which this research would not have been possible.

\section{REFERENCES}

Arreola, AG, Balaban, MO, Marshall M, Peplow A, Wei CI, and Cornell J. 1990 Supercritical Carbon Dioxide Effects on Some Quality Attributes of Single Strength Orange Juice. J. Food Sc. 56:1030-1033.

Ballestra P. and Cuq JL. 1998 Influence of Pressurized Carbon Dioxide on the Thermal Inactivation of Bacterial and Fungal Spores. Lebensm.-Wiss. u.Technol., 31: 84-88.

Bridson EY 1998 The Oxoid Manual. $8^{\text {th }}$ edn, Oxoid Limited, Hampshire.

Devlieghere F, and Debevere J 2000 Influence of Dissolved Carbon Dioxide on the Growth of Spoilage Bacteria. Lebensm.-Wiss. u.-Technol. 33: 531537.

Erkmen O 2000a Inactivation of Salmonella typhimurium by high pressure carbon dioxide. Food Microbiol. 17: 225-232.

Erkmen O 2000b Effect of carbon dioxide pressure on Listeria monocytogenes in physiological saline and foods. Food Microbiol. 17: 589-596.

Erkmen O 2000c Antimicrobial effects of pressurized carbon dioxide on Brochothrix thermosphacta in broth and foods. J Sci Food Agri, 80: 1365-1370.

Erkmen, O. 2000d, Antimicrobial effects of pressurized carbon dioxide on Enterococcus faecalis in saline and foods. J Sci Food Agri, 80: 465-470.

Erkmen O 2000e Predictive modeling of on Listeria monocytogenes Inactivation Under High Pressure Carbon Dioxide. Lebensm.-Wiss. u.-Technol. 33: 514519.

Erkmen O 1997 Antimicrobial Effects of Pressurized Carbon Dioxide on Staphylococcus aureus in Broth and Milk. Lebensm.-Wiss. u.-Technol. 30: 826-829.

Hong A, Park W, and Pun Y 1997 Inactivation of Lactobacillus sp. from Kimchi by High Pressure Carbon Dioxide. Lebensm.-Wiss. u.-Technol. 30: 681-685.

Karaman H, and Erkmen O 2001 High carbon dioxide pressure inactivation kinetics of Escherichia coli in broth. Food Microbiology 18: 11-16.

Park SJ, Lee JI, and Park J 2002 Effects of a Combined Process of High-Pressure Carbon Dioxide and High Hydrostatic Pressure on the Quality of Carrot Juice. JFS: Food Eng. Phys. Prop. 67: 18271834 